\title{
Challenges and Facilitators to Providing Health Care Services to Pregnant Women who use Drugs: The perspective of health care professionals
}

\author{
Kelly Boyd
}

\section{INTRODUCTION}

Although the delivery of prenatal health care services continues to improve in Canada, pregnant women within vulnerable populations often do not receive adequate prenatal care from health care professionals. Women who use both illegal and prescription drugs during pregnancy are considered to be one of these vulnerable populations. Previous research has repeatedly focused on the challenges experienced by the women themselves when seeking prenatal care however; there is a lack of information from the perspectives of health care professionals. Frameworks that encourage positive and trusting relationships must be developed to improve communication among health care professionals and pregnant drug users 1 . While there is a general agreement that negative attitudes towards this population of women are prevalent among health care professionals, few suggestions have been made as to how to improve attitudes of health care professionals 2,3. Exploring the perspectives of health care professionals will help to further determine the challenges and facilitators to providing health care services to this population of women and what can be done to overcome the identified challenges. This will also improve the delivery of health care services, provide evidence that will help guide future programs and policies, and will assist in improving the communication gap between health care professionals from

*To whom correspondence should be addressed:

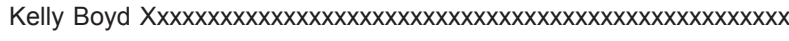

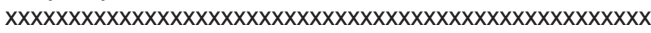

different disciplines. The purpose of this study was to explore the perspectives of health care professionals in regards to providing health care services to pregnant women who use illegal and prescription drugs and to gain a further insight into their experiences in working with this population of women. The study explored the following research questions:

1. What do health care professionals perceive as the challenges to providing health care services to pregnant women who use drugs?

2. What facilitates the delivery of health care services to this specified population of vulnerable women?

3. What do health care professionals suggest should be done to overcome the identified challenges?

\section{METHODS}

To further explore the perspectives of health care professionals and the diversity of their experiences, a qualitative research approach incorporating a grounded theory design was used. Five health care professionals (two nurses, one clinical nurse specialists, and two obstetricians) were recruited using email and poster distribution from the Perinatal Centre and Birth Unit within the largest maternal and child health care center in the Maritimes, the IWK Health Centre in Halifax, Nova Scotia. Eligible participants included health care professionals who have had previous experience working with women who used illicit and/or prescription drugs during their pregnancy. Data were collected using in depth, semi-structured, 
Table 1. Challenges to Providing Health Care Services

\begin{tabular}{|l|l|l|l|l|}
\hline Core Category & \multicolumn{3}{|c|}{ Challenges to Providing Health Care Services } \\
\hline Themes & $\begin{array}{l}\text { Building Relation- } \\
\text { ships }\end{array}$ & Continuity of Care & Time & $\begin{array}{l}\text { Differences in Health } \\
\text { Care }\end{array}$ \\
\hline Sub-Themes & $\begin{array}{l}\text {-Gaining Trust } \\
\text {-Trust in Health Care } \\
\text { Systems } \\
\text {-Trust in Health Care } \\
\text { Professionals }\end{array}$ & $\begin{array}{l}\text { •Compliance with ap- } \\
\text { pointments } \\
\bullet \text { Spectrum of Women } \\
\text { (i.e. incarcerated } \\
\text { women \& prostitutes) }\end{array}$ & $\begin{array}{l}\text { •Women need the most } \\
\text { amount of time } \\
\text { •Willing to give the } \\
\text { least amount of time } \\
\bullet \text { Point at which prena- } \\
\text { tal care is sought }\end{array}$ & Different Concerns \\
\hline
\end{tabular}

face-to-face interviews. The interviews took place within the IWK during the months of March and April 2010, each lasting between 20 and 40 minutes.

Interviews were audio recorded and transcribed verbatim by a transcriptionist. To compare views, experiences, and actions, the constant comparative method of the grounded theory approach was used to analyze the data 4,5. Interview transcripts were analyzed using open coding (comparison within a single interview), axial coding (comparisons between interviews), and selective coding (refines the themes into an explanatory scheme) 5,6. Ethical approval for this research study was obtained from the IWK Research Ethics Board under the expedited review category. Consent was obtained using a written consent form prepared according to specific IWK protocol.

\section{RESULTS}

Findings revealed challenges included building relationships with the women, the continuity of care, the amount of extra time that the women require, and the differences in care. Table 1 includes the sub-themes that emerged within the identified challenges.

Facilitators to providing care to this population of women included the opportunity to attend multidisciplinary educational workshops, experience as a health care professional, the clinical nurse specialist who works within the IWK, and the positive support systems available in the women's lives. Among these identified themes, numerous sub themes also emerged. Table 2 provides an overview of the facilitators that were discussed.

To overcome the identified challenges, participants indicated more educational workshops would be beneficial, working on a one-on-one basis with the women to better address individual concerns and tailor the delivery of care, and enhancing collaboration with community organizations.

\section{DISCUSSION}

The overall findings from this research study indicate that there are several challenges associated with the delivery of health care to pregnant women who use illicit and prescription drugs. In terms of relationships and time, the results of this study were relatively similar to the findings in the relevant literature 1. Health care professionals stress that relationships are critical and in order to build relationships, there is need for trust. There is also an agreement surrounding the challenge of time. Pregnant women who use drugs are willing to give health care professionals the least amount of time however; they need the most amount of time. This creates a problem because the women often do not get all the health services that they need in the short amount of time that they are willing to donate. While both participants in this study and existing literature mentioned differences in care, previous studies indicated that specialized care was needed and often could not be obtained therefore, challenges to providing care developed 1,7. Although differences in providing care were mentioned by the participants in this particular study, the need for specialized care was not a concern.

In terms of facilitators, the participants in this study indicated that attending educational workshops that focus on pregnancy and substance use are especially beneficial however, this was not mentioned in any existing literature. A surprising facilitator found within this study was the clinical nurse specialist who works within the IWK. There was nothing like this mentioned in the reviewed literature that I know of.

The findings from this study provide evidence that can assist in the formation of new programs or policies surrounding pregnancy and drug use in order to improve the delivery of care. 
Table 2. Facilitators to Providing Health Care Services

\begin{tabular}{|l|l|l|l|l|}
\hline \multicolumn{1}{|c|}{ Core Category } & \multicolumn{4}{|c|}{ Facilitators to Providing Health Care Services } \\
\hline Themes & $\begin{array}{l}\text { Educational Work- } \\
\text { shops }\end{array}$ & $\begin{array}{l}\text { Professional Experi- } \\
\text { ence }\end{array}$ & $\begin{array}{l}\text { Clinical Nurse Spe- } \\
\text { cialist }\end{array}$ & $\begin{array}{l}\text { Positive Support } \\
\text { Systems }\end{array}$ \\
\hline Sub-Themes & $\begin{array}{l}\text {-More Awareness } \\
\text {-Multidisciplinary } \\
\text { aproach }\end{array}$ & $\begin{array}{l}\text { Strategies } \\
\text { •More Services }\end{array}$ & $\begin{array}{l}\text {-Coordinates the Care } \\
\text { Process } \\
\bullet \text { Collaborates }\end{array}$ & •Family \\
\hline
\end{tabular}

Limitations of this study include small sample size, health care professionals from within one hospital, and the limited diversity of the healthcare professionals who participated. Future research in this area should incorporate several levels of health care professionals (i.e. recent graduates all the way to very experienced professionals in the field) and be conducted over a longer period of time. An interesting concept that emerged from the data was the importance of collaboration with health care professionals from outside the immediate hospital environment. An interdisciplinary approach is important for future studies in order to develop the most effective care practices.

\section{REFERENCES}

1. Morton, J., Konrad Cohen, S. (2009). Introducing a caring/ relational framework for building relationships with addicted mothers. Journal of Obstetric, Gynecologic, and Neonatal Nursing (JOGNN), 38, 206-213. doi: 10.1111/j.1552.6909. 2009.01006.x

2. Klee, H., Jackson, M., Lewis. S. (2002). Drug misuse and motherhood. Practitioner views of pregnant drug users (pp.105-122). New York: Routledge.

3. Raeside, L. (2003). Attitudes of staff towards mothers affected by substance abuse. British Journal of Nursing, 12(5), 302-310.

4. Baumgartner, T.A., Hensley, L.D. (2006). Conducting and reading research in health and human performance. Boston: McGraw Hill.

5. Charmaz, K. (2000). Ground theory: Objective and constructivist methods. In N.K. Denzin \& Y.S. Lincoln (Eds), Handbook of qualitative research (pp. 509-536). California: Sage Publication, Inc.

6. Leedy, P. \& Ormrod, J. (2010). Practical Research: Planning and Design. 9th Ed. New Jersey: Pearson Prentice Hall.

7. Fraser, J.A., Barnes, M., Biggs, H.C. \& Kain, V.J. (2006). Caring, chaos and the vulnerable family: Experiences in caring for newborns of drug-dependent parents. International Journal of Nursing Studies, 44, 1363-1370. doi: 10.1016/j.ijnurstu.2006.06.004 